\title{
The effects of a community-based pulmonary rehabilitation programme on exercise tolerance and quality of life: a randomized controlled trial
}

\author{
W. Cambach*, R.V.M. Chadwick-Straver*++, R.C. Wagenaar*++, \\ A.R.J. van Keimpema+, H.C.G. Kemper ${ }^{+}$
}

\begin{abstract}
The effects of a community-based pulmonary rehabilitation programme on exercise tolerance and quality of life: a randomized controlled trial. W. Cambach, R.V.M. Chadwick-Straver, R.C. Wagenaar, A.R.J. van Keimpema, H.C.G. Kemper. @ERS Journals Ltd 1997.

ABSTRACT: The present multicentre study evaluates the differences in efficacy between a 3 month rehabilitation programme including drug treatment, and a 3 month control period of drug treatment only, for asthmatic patients and patients with chronic obstructive pulmonary disease (COPD). The programme was run by physiotherapists in eight local practices, and included exercise training, patient education, breathing retraining, evacuation of mucus, relaxation techniques, and recreational activities.

In a randomized controlled trial with a cross-over design, the effects of rehabilitation were evaluated 3 and 6 months after baseline measurements in terms of exercise tolerance and quality of life (QOL). Exercise tolerance was assessed using submaximal cycle ergometer tests and 6 min walking tests. QOL was evaluated by means of the Chronic Respiratory Disease Questionnaire (CRDQ).

After 3 months, the patients who started with rehabilitation showed significant improvements in endurance time (421 s) and cardiac frequency $\left(6\right.$ beats $\left.\cdot \mathrm{min}^{-1}\right)$ during cycling, walking distance $(39 \mathrm{~m})$, and total CRDQ score (17 points) compared to the control group. These improvements were still significant after 6 months. Additional analysis indicated that the asthmatic patients and the patients with COPD responded to rehabilitation in a similar way, with the exception that there was a greater improvement in walking distance for asthmatics. Improvements in exercise tolerance were not significantly correlated with improvements in QOL.

Rehabilitation of patients with asthma or chronic obstructive pulmonary disease in local physiotherapy practices improves exercise tolerance and quality of life.

Eur Respir J., 1997; 10: 104-113.
\end{abstract}

\author{
Dept of *Physiotherapy and **Pulmonary \\ Diseases of the VU Hospital, +Health Sci- \\ ence with respect to Human Movement, \\ Faculty of Human Movement Sciences of \\ the Vrije Universiteit, and ${ }^{++}$Institute for \\ Fundamental and Clinical Human Move- \\ ment Sciences, Amsterdam, The Nether- \\ lands. \\ Correspondence: W. Cambach \\ Dept of Physiotherapy VU Hospital \\ p/o box 7057 \\ 1007 MB Amsterdam \\ The Netherlands \\ Keywords: Community Health Services \\ exercise tolerance \\ lung diseases \\ physiotherapy \\ quality of life \\ rehabilitation
}

Received: August 281995

Accepted after revision September 291996
The benefits of in-patient rehabilitation programmes [1], out-patient rehabilitation programmes [2], and home exercise programmes [3] for patients with chronic obstructive pulmonary disease (COPD) have been described in randomized controlled studies. These studies report significant improvements in exercise tolerance [1-3], and/or quality of life (QOL) [1,3]. Such improvements are generally considered to be the major objectives of pulmonary rehabilitation $[4,5]$. The purpose of the present study was to evaluate the efficacy of pulmonary rehabilitation in a community-based setting in local physiotherapy practices.

In general, patients with severe airflow obstruction are considered for treatment by rehabilitation in asthma centres or out-patient/in-patient hospital settings with the required facilities (e.g. oxygen therapy). For patients with mild to moderately severe airflow limitation, rehabilitation programmes implemented in local physiotherapy practices may suffice [6]. Given the simple testing and training methods, and their implementation in a community-based setting, these programmes do not require the provision of expensive resources. In addition, these programmes have the advantage of easy accessibility and can be attended by patients in their own locality. In the Netherlands, many physiotherapists work in local practices. After examination and referral by a pulmonary physician, these physiotherapists carry their own legal responsibility for their patients during the rehabilitation sessions.

StriJbos et al. [7] evaluated, in a group of COPD patients (mean forced expiratory volume in one second (FEV1) $1.0 \mathrm{~L}$ ), the effects of a 3 month rehabilitation programme. They compared the effects of: 1) treatment in a home-based setting (in total $27 \mathrm{~h}$ ) in combination with 24 treatment sessions in a local physiotherapy practice (in total $12 \mathrm{~h}$ ); 2) treatment in an out-patient department (in total $24 \mathrm{~h}$ ) in combination with daily exercises at home (in total $21 \mathrm{~h}$ ); and 3) a no treatment 
condition. In both treatment groups, statistically significant improvements were found in maximal load during an incremental bicycle ergometer test and general well-being (as assessed by a self-constructed questionnaire) in comparison with the control group. No such differences between the treatment groups and the control group were found in 4 min walking distance.

WIJKSTRA et al. [3] evaluated, in a group of COPD patients (mean FEV1 1.2 L), the effects of a 3 month community-based rehabilitation programme. The patients in the experimental group carried out a daily exercise programme at home (in total $84 \mathrm{~h}$ ) and received 24 sessions in a local physiotherapy practice (in total 12 h). A control group did not follow this programme. The study demonstrated significant differences between groups in terms of the maximal load during an incremental bicycle ergometer test and the dimensions dyspnoea, emotions, and mastery of the Chronic Respiratory Disease Questionnaire (CRDQ) [8], in favour of the patients who received the rehabilitation programme.

In a preliminary study, CAMBACH et al. [6] showed the feasibility of a rehabilitation programme which was run exclusively in local physiotherapy practices in terms of: 1) recruitment of physiotherapists, general practitioners and patients; and 2) preliminary effects of the programme. Statistically significant improvements were observed in endurance time during cycling and in the CRDQ dimensions dyspnoea, fatigue, emotions and mastery.

In the present study, the objective was to determine the differences in efficacy between a rehabilitation programme, run in local physiotherapy practices, that included drug treatment, and a control condition of drug treatment only.

\section{Patients and methods}

\section{Patients}

Between June 1992 and July 1994, 130 patients were referred for pulmonary rehabilitation in local physiotherapy practices. Patients were recruited by their general practitioner or pulmonary physician. Before entry into the programme, each patient underwent a physical, laboratory and lung function examination, and an incremental exercise test. The following admission criteria were used: 1) evidence of dyspnoea and decreased exercise tolerance as a result of obstructive lung disease; 2) age $18-75 \mathrm{yrs} ; 3$ ) ability to travel independently to the physiotherapy practice; 4) medication prescribed by a pulmonary physician; 5) no manifest cardiac complaints or locomotor disabilities; 6) absence of hypercapnia; arterial carbon dioxide tension $\left(P \mathrm{a}, \mathrm{CO}_{2}\right)>6.0 \mathrm{kPa}(45$ $\mathrm{mmHg})$ ) and/or hypoxia; arterial oxygen tension $\left(\mathrm{Pa}, \mathrm{O}_{2}\right.$ $<8.7 \mathrm{kPa}(65 \mathrm{mmHg}))$ during rest and/or maximal bicycle exercise testing; 7) motivation to improve self-care; and 8) informed consent. Fourteen patients dropped out before medical examination (i.e. six patients became ill, three patients found the session frequency too high, two patients died, two patients refused to take part in the incremental exercise test, and one patient moved from the area). In addition, 17 patients were excluded after medical examination (i.e. 15 patients because of hypoxaemia, and two patients not meeting the diagnostic criteria of "obstructive pulmonary disease"). The data of the remaining 99 patients are discussed below. The study was approved by the Ethics Board of the VU hospital.

\section{Study design}

The study involved a randomized, controlled trial with a cross-over design over a 6 month period. One group of patients started with a 3 month rehabilitation programme including drug treatment, followed by a 3 month control period during which only drug treatment was applied (group RC). The other group underwent an initial 3 month control period of drug treatment alone, and subsequently a 3 month rehabilitation programme including drug treatment (group CR). Since eight local physiotherapy practices were involved, this study was a multicentre trial. Within each physiotherapy practice, four out of eight patients were randomly allocated to group $\mathrm{RC}$, and four patients to group CR (block randomization procedure; four closed envelopes for condition RC and four closed envelopes for condition CR). Baseline assessments were carried out prior to randomization $(t 0)$. These assessments were repeated 3 months $(t 3)$ and 6 months ( $t 6)$ after the start of the programme.

A posteriori, the patients were divided into diagnostic groups according to the diagnosis of the referring and supervising pulmonary physician (ARJK). The patients were labelled as having asthma in case of the presence of complaints of dyspnoea, occurring periodically, with varying severity, at the present time or in the past, in combination with an increase in FEV1 of at least $15 \%$ after bronchodilation, or a histamine threshold (provocative concentration producing a $20 \%$ fall in FEV1 (PC20)) of $\leq 8 \mathrm{mg} \cdot \mathrm{mL}^{-1}$. Patients were labelled as having COPD when they suffered from stable dyspnoea, as well as coughing and/or production of mucus, in combination with a decreased FEV1/vital capacity (VC) ratio [9]. As patients were not classified at the outset of the study, randomization was not stratified for diagnosis.

\section{Assessments}

Incremental cycle ergometer test. Prior to the assessments in the physiotherapy practices, an incremental exercise test was performed by a pulmonary physician using a calibrated, electrically-braked cycle ergometer (KEM 3, Mijnhardt, The Netherlands). The power output was initially $20 \mathrm{~W}$ and was increased every minute by $10-20 \mathrm{~W}$ until the maximal attainable load was reached. Minute ventilation $\left(V^{\prime} \mathrm{E}\right)$, oxygen uptake $\left(V^{\prime} \mathrm{O}_{2}\right)$, and carbon dioxide production $\left(V^{\prime} \mathrm{CO}_{2}\right)$ were measured breathby-breath (Medical Graphics Corp., St. Paul, USA). The cardiac frequency $(f \mathrm{C})$ was measured continuously. At rest and at maximal exercise, arterial blood samples were taken for analysis of blood gas tensions $\left(\mathrm{Pa}_{\mathrm{a}} \mathrm{O}_{2}\right.$ and $\left.P \mathrm{a}, \mathrm{CO}_{2}\right)$. Spirometric results (FEV1) were compared to normal values (FEV1\% predicted) derived from the European Community for Coal and Steel (ECCS) [9]. The percentage of predicted maximal workload $(W \max \%$ 
pred) was derived from Jones et al. [10]. This test was carried out once at baseline in order to determine which patients met the inclusion criteria as well as to derive individually gauged training intensities.

Endurance cycle ergometer test. An endurance cycle ergometer test was performed on a mechanically-braked, calibrated cycle ergometer (Monark, Bodyguard 814E, Varberg, Sweden). The patients were asked to cycle at $75 \%$ of their maximal power output $\left(W_{\max }\right)$ until exhaustion; the endurance time was used as the assessment parameter. The score on a 10-point Borg category scale [11] was registered each minute, and the patient was informed about the time that had elapsed. The maximal cycling time was $20 \mathrm{~min}$. In order to control for motivational aspects during this test, a record was made of whether or not the patient met the following criteria: 1) a score of at least 9 on the Borg scale for the variables perceived exertion and/or dyspnoea-sensation. In our experience, all patients with relatively mild asthma or COPD are able to reach Borg scores of 9 to maximum during the endurance cycle ergometer test $(\mathrm{CAMBACH}$ et al. [6]); 2) a $f \mathrm{C}$ above $85 \%$ of that maximally attained during the maximal cycle ergometer test; and 3) a cycling frequency above 50 revolutions $\cdot \mathrm{min}^{-1}$. Patients were excluded from further data analysis when they did not meet two or more of the criteria at the last minute of the test. Although, the reliability and validity of this test for patients with asthma or COPD has not yet been evaluated, a number of investigators have demonstrated the sensitivity of endurance cycle ergometer tests in detecting changes in endurance time [12-14].

Submaximal cycle ergometer test. A submaximal cycle ergometer test was carried out on a mechanicallybraked, calibrated cycle ergometer (Monark 814E). The mean $f \mathrm{C}$ during the sixth minute of cycling at $60 \%$ of the maximal load achieved during the incremental exercise test $\left(60 \% W_{\max }\right)$ was evaluated with a sport tester (Polar Elektro, Oy, Kempele, Finland). A reduction in $f \mathrm{C}$ at the same workload, was considered to be an improvement in the function of the cardiovascular system [15]. To our knowledge, the reliability and validity of this test for patients with asthma or COPD has not yet been established. CASABURI et al. [13] have demonstrated the sensitivity of a submaximal cycle ergometer test in detecting changes in $f \mathrm{C}$.

Six minute walking test. During a 6 min walking test [16], the patients were instructed to cover as much distance as possible. The test was carried out under standardized conditions to ensure consistency in encouragement and subject motivation [17]. Two practice 6 min walks preceded a third walk to avoid any learning effect. Since Mungall and Hainsworth [18] did not find a significant additional improvement in walking distance after a third walking test, the result of the third walk was used in the analysis.

\section{Chronic Respiratory Disease Questionnaire (CRDQ)}

An interviewer administered the CRDQ, which comprised the dimensions: dyspnoea (score 5-35); fatigue
(4-28); emotion (7-49); and mastery (4-28). For this purpose, the CRDQ was translated into Dutch. GuYATT et al. [8] showed the reproducibility of the CRDQ by means of the coefficient of variation (i.e. the withinperson standard deviation divided by the mean). They found values of $6 \%$ for the dyspnoea dimension, $9 \%$ both for fatigue and emotional function, and $12 \%$ for mastery. In addition, GosselinK et al. [12] demonstrated the test-retest reliability of the four dimensions of the Dutch version. Spearman's rank correlation coefficients were: $r=0.74$ for dyspnoea; $r=0.93$ for fatigue; $r=0.98$ for emotion; and $\mathrm{r}=0.80$ for mastery.

The patients underwent two practice 6 min walking tests, with at least $30 \mathrm{~min}$ of rest between the two. The submaximal cycle ergometer test and the endurance cycle ergometer test were carried out on nonconsecutive days. There was a rest period of at least $45 \mathrm{~min}$ between these tests, during which the CRDQ was completed. Again on nonconsecutive days, the third 6 min walking test was performed.

Data obtained from patients who did not return for one or more of the assessments (i.e. baseline $(t 0)$, after 3 months ( $t 3)$ and/or after 6 months ( $t 6)$ ), or patients who were not measured within 3 weeks (from $t 0, t 3$ and $t 6$ ) were excluded from data analysis.

\section{Rehabilitation programme}

The patients with asthma or COPD received the same rehabilitation programme, comprising techniques of breathing retraining and evacuation of mucus, exercise training (both for lower and upper extremities), patient education, relaxation techniques and recreational activities. Although the physiotherapists followed strict guidelines with respect to all components of the programme, allowances were made for individual needs. In each physiotherapy practice, 3-4 participants attended group sessions 3 days a week for $90 \mathrm{~min}$. The exercise training was performed twice a week on a cycle ergometer (Monark 814E), on a rowing machine (Kettler Favorit 220; Heinz Kettler, Ense-Parsit, Germany), and by stair-walking. During the programme, a bicycle training scheme was used in which: 1) the intensity progressively increased from 60 to $75 \% W_{\max }$; and 2) the duration increased from $3 \mathrm{~min}$ to $12 \mathrm{~min} \mathrm{[19].} \mathrm{We} \mathrm{aimed} \mathrm{at} \mathrm{an} \mathrm{intensity}$ in the "rowing" and "walking up- and downstairs" exercises of $60 \%$ or more of maximum $f \mathrm{C}$, directed by the physiotherapists. The duration of these latter activities was extended during treatment from 3 min in Week 1 , to $5 \mathrm{~min}$ in Week 12. Recreational activities were conducted once a week for $45 \mathrm{~min}$. The purpose of the recreational activities was to direct participants toward regular physical activities deemed essential to maintain benefits after rehabilitation. Hence, activities were chosen in line with the patient's interests, such as swimming, cycling and hockey. The aim was to achieve an intensity of recreational activity producing $60 \%$ or more of maximum $f \mathrm{C}$ for at least $30 \mathrm{~min}$. Patient education sessions were chaired by district nurses, and relaxation sessions were held every week for $45 \mathrm{~min}$. To ensure the quality and the consistency of the rehabilitation programme, all physiotherapists participated in a course on pulmonary rehabilitation, during which 
they were taught the protocol. CAMBACH et al. [6] have previously presented a more detailed description of the rehabilitation programme.

\section{Statistical analysis}

The following findings would support the hypothesis that the rehabilitation programme is beneficial in terms of exercise tolerance and QOL: 1) during the first 3 months $(t 0-t 3)$ group $\mathrm{RC}$ should show a larger improvement compared to group CR; 2) group RC should show a larger improvement during the rehabilitation period $(t 0-t 3)$ compared to the control period $(t 3-t 6) ; 3)$ group CR should show a larger improvement during the rehabilitation period $(t 3-t 6)$ compared to the control period $(t 0-t 3)$; 4) group RC should show improvement in follow-up measurements $(t 6)$ in comparison with baseline measurements $(t 0)$.

Differences in baseline outcome measures between groups were analysed using the Wilcoxon rank-sum test. Two-way analysis of variance (ANOVA) with repeated measurements was used to establish the significant effects of group, time, and interaction of time with group. If a statistically significant interaction of time with group was found, the following post-hoc analyses were performed: 1) a between-group ( $\mathrm{RC}$ versus $\mathrm{CR}$ ) comparison with respect to the first 3 months of the design using a contrast analysis (hypothesis 1);2) a within-group comparison between rehabilitation and control periods using Wilcoxon signed-rank test (hypotheses 2 and 3); and 3) a comparison between follow-up and baseline measurements for group $\mathrm{RC}$, again using the Wilcoxon signed-rank test (hypothesis 4). Changes within group $\mathrm{RC}$ between the third and sixth month were analysed using the Wilcoxon signed-rank test. To evaluate significant differences between patients with asthma and COPD over 6 months, diagnosis (asthma or COPD) was included as a constant covariate in the ANOVA with repeated measurements. The effects of the within-group analyses were tested one-sided. For all tests BMDP (Statistical Software Inc., Los Angeles, 1990) was applied, using a significance level of 0.05 .

Spearman's rank correlation coefficients were calculated in order to establish possible relationships between exercise tolerance and QOL. Since correlation coefficients were calculated for a large number of variables, a significance level of 0.01 was used.

\section{Results}

Before randomization, 10 of the 99 patients who met the inclusion criteria dropped out (four patients found the intensity of the programme and/or frequency of three sessions a week too high, four patients became ill, one patient moved from the area, and one patient refused to take part in the programme since her dyspnoea ameliorated). After randomization, 46 patients were assigned to group RC and 43 to group CR. During the treatment sessions, nine patients from group $\mathrm{RC}$ and 14 patients from group CR dropped out (11 patients became ill, five patients found the intensity and/or frequency of the programme too high, three patients obtained a full-time job, two patients could not be tested within 3 weeks, one patient did not complete the final assessments, and one patient broke her arm).

Thus, 37 patients remained in group RC and 29 in group CR. In table 1 , the baseline characteristics of the entire group of 66 patients and of 23 patients with asthma and 43 patients with COPD are presented separately. Baseline characteristics of the patients who dropped out (age 53 \pm 12 yrs; 14 males and 19 females; FEV1 $2.1 \pm 0.8 \mathrm{~L} ; \mathrm{FEV} 1$ pred $71 \pm 24 \%$; $W \max 113 \pm 32 \mathrm{~W} ; W_{\max }$ $83 \pm 22 \%$ pred) were not significantly different from those of the 66 patients who completed the programme (groups RC and $\mathrm{CR} ; \mathrm{p}>0.15$ ). Baseline characteristics differed significantly between groups $\mathrm{RC}$ and $\mathrm{CR}$ in age in the mixed group (patients with asthma or COPD; $\mathrm{p}=0.04$ ) and in age and FEV1 in the patients with asthma $(p<0.009)$. The other baseline characteristics were not significantly different between groups RC and CR $(p>0.11)$. Finally, neither the mean number of weeks of the rehabilitation programme attended by groups $\mathrm{RC}$ and CR (mixed group 10.7 \pm 1.6 vs $10.3 \pm 1.5$; asthmatics $10.3 \pm 1.7$ vs $10.0+1.3$; patients with COPD $11 \pm 1.3$ vs $10.7+$ 2.0 , respectively; $\mathrm{p}>0.31$ ) nor the mean number of exacerbations (mixed group $0.6 \pm 0.8$ vs $0.8 \pm 1.0$; asthmatics $0.8 \pm 0.8$ vs $0.9 \pm 1.1$; patients with COPD $0.5 \pm 0.6$ vs $0.6 \pm$ 0.7 , respectively; $p>0.68$ ) were significantly different.

Table 1. - Baseline characteristics of patients who completed the rehabilitation programme (groups RC and CR)

\begin{tabular}{|c|c|c|c|c|c|c|c|c|c|}
\hline \multirow[t]{2}{*}{ Variable } & \multicolumn{3}{|c|}{ Asthma and COPD } & \multicolumn{3}{|c|}{ Asthma } & \multicolumn{3}{|c|}{ COPD } \\
\hline & $\mathrm{RC}$ & $\mathrm{CR}$ & $\mathrm{RC}+\mathrm{CR}$ & $\mathrm{RC}$ & $\mathrm{CR}$ & $\mathrm{RC}+\mathrm{CR}$ & $\mathrm{RC}$ & $\mathrm{CR}$ & $\mathrm{RC}+\mathrm{CR}$ \\
\hline Patients $\mathrm{n}$ & 37 & 29 & 66 & 22 & 21 & 43 & 15 & 8 & 3 \\
\hline Gender $\mathrm{M} / \mathrm{F}$ & $11 / 26$ & $13 / 16$ & $24 / 42$ & $4 / 18$ & $7 / 14$ & $11 / 32$ & $7 / 8$ & $6 / 2$ & $13 / 10$ \\
\hline Age yrs & $49 \pm 14$ & $55 \pm 15 *$ & $52 \pm 15$ & $40 \pm 10$ & $53 \pm 15^{*}$ & $46 \pm 14$ & $62 \pm 5$ & $62 \pm 9$ & $62 \pm 7$ \\
\hline FEV1 L & $2.3 \pm 0.8$ & $2.2 \pm 0.8$ & $2.2 \pm 0.8$ & $2.8 \pm 0.6$ & $2.3 \pm 0.8 *$ & $2.6 \pm 0.7$ & $1.5 \pm 0.4$ & $1.8 \pm 0.7$ & $1.6 \pm 0.5$ \\
\hline $\mathrm{FEV}_{1} \%$ pred & $77 \pm 22$ & $77 \pm 23$ & $77 \pm 22$ & $89 \pm 17$ & $84 \pm 20$ & $86 \pm 18$ & $59 \pm 16$ & $60 \pm 23$ & $59 \pm 18$ \\
\hline$W_{\max } \quad \mathrm{W}$ & $124 \pm 34$ & $134 \pm 39$ & $129 \pm 42$ & $140 \pm 31$ & $139 \pm 46$ & $140 \pm 39$ & $101 \pm 39$ & $121 \pm 44$ & $108 \pm 41$ \\
\hline$W_{\max } \%$ pred & $86 \pm 26$ & $95 \pm 28$ & $90 \pm 27$ & $92 \pm 24$ & $101 \pm 24$ & $96 \pm 24$ & $77 \pm 27$ & $81 \pm 34$ & $78 \pm 29$ \\
\hline
\end{tabular}

Values are expressed as the mean \pm SD. FEV1: forced expiratory volume in one second; $W$ max: maximal workload of the progressive exercise test; \% pred: percentage of predicted value; M: male; F: female; COPD: chronic obstructive pulmonary disease; $\mathrm{RC}$ : group that started with a 3 month rehabilitation programme including drug treatment, followed by a 3 month control period of drug treatment only; CR: group that underwent a 3 month control period of drug treatment alone, followed by a 3 month rehabilitation programme including drug treatment. *: $\mathrm{p}<0.05$, significant difference between group RC and group CR. 
Table 2. - Baseline values and changes from baseline for all patients (asthma and COPD) in the rehabilitation-control group $(\mathrm{RC})$ and in the control-rehabilitation group $(\mathrm{CR})$ with respect to exercise tolerance and quality of life

\begin{tabular}{|c|c|c|c|c|}
\hline \multirow[t]{2}{*}{ Variable } & \multirow[t]{2}{*}{ Group } & \multicolumn{3}{|c|}{ Measurements } \\
\hline & & Baseline & After 3 months & After 6 months \\
\hline \multicolumn{5}{|l|}{ Exercise tolerance } \\
\hline \multirow[t]{2}{*}{ Endurance time during cycling at $75 \% W \max s$} & $\mathrm{RC}(\mathrm{n}=35)$ & $377 \pm 181$ & $417 \pm 231 * * \dagger \dagger$ & $215 \pm 323$ \\
\hline & $\mathrm{CR}(\mathrm{n}=25)$ & $369 \pm 201$ & $-4 \pm 186$ & $448 \pm 219 \dagger \dagger$ \\
\hline \multirow[t]{2}{*}{$f_{\mathrm{C}}$ during cycling at $60 \% \mathrm{~W} \max$ beats $\cdot \mathrm{min}^{-1}$} & $\mathrm{RC}(\mathrm{n}=37)$ & $134 \pm 24$ & $-7 \pm 12 * \dagger$ & $-5 \pm 12$ 蛙 \\
\hline & CR $(n=26)$ & $135 \pm 19$ & $-1 \pm 6$ & $-10 \pm 8^{\dagger \dagger}$ \\
\hline \multirow[t]{2}{*}{ Walking distance $\mathrm{m}$} & $\mathrm{RC}(\mathrm{n}=30)$ & $551 \pm 129$ & $58 \pm 77 * \dagger$ & $59 \pm 92 \ddagger$ \\
\hline & $\mathrm{CR}(\mathrm{n}=24)$ & $596 \pm 135$ & $19 \pm 60$ & $69 \pm 66$ \\
\hline \multicolumn{5}{|l|}{ Quality of life } \\
\hline \multirow[t]{2}{*}{ Dyspnoea score (range 5-35) } & $\mathrm{RC}(\mathrm{n}=36)$ & $19 \pm 6$ & $6 \pm 5 * * \dagger \dagger$ & $7 \pm 6+$ \\
\hline & $\mathrm{CR}(\mathrm{n}=28)$ & $18 \pm 5$ & $1 \pm 3$ & $6 \pm 5^{\dagger \dagger}$ \\
\hline \multirow[t]{2}{*}{ Fatigue score (range 4-28) } & $\mathrm{RC}(\mathrm{n}=37)$ & $16 \pm 5$ & $4 \pm 5 * * \dagger \dagger$ & $5 \pm 6+$ \\
\hline & CR $(n=29)$ & $17 \pm 5$ & $0 \pm 3$ & $3 \pm 5^{\dagger}$ \\
\hline \multirow[t]{2}{*}{ Emotion score (range 7-49) } & $\mathrm{RC}(\mathrm{n}=37)$ & $29 \pm 8$ & $6 \pm 7 *+\dagger$ & $7 \pm 9+$ \\
\hline & $\mathrm{CR}(\mathrm{n}=29)$ & $32 \pm 7$ & $1 \pm 5$ & $4 \pm 7$ \\
\hline \multirow[t]{2}{*}{ Mastery score (range 4-28) } & $\mathrm{RC}(\mathrm{n}=37)$ & $19 \pm 6^{\$}$ & $4 \pm 4 * *+\dagger$ & $4 \pm 5+$ \\
\hline & $\mathrm{CR}(\mathrm{n}=29)$ & $22 \pm 5$ & $0 \pm 3$ & $1 \pm 3^{\dagger}$ \\
\hline
\end{tabular}

Values are expressed as the mean \pm SD. $f \mathrm{C}$ : cardiac frequency. For further definitions see legend to table $1 . \$$ : $p<0.05$, compared to group CR (Wilcoxon rank-sum test); *: $<<0.05$; and $* *: \mathrm{p}<0.001$, compared to group CR (ANOVA); ${ }^{\dagger}: \mathrm{p}<0.05$; and ${ }^{\dagger}: \mathrm{p}<0.001$, compared to control period (Wilcoxon signed-rank test); $\ddagger$ : $<0.05$; and $\$$ : $p<0.001$, compared to baseline (Wilcoxon signed-rank test).

\section{Exercise tolerance}

Mean values of baseline exercise tolerance (i.e. endurance time during cycling at $75 \% W \max , f \mathrm{C}$ during cycling at $60 \% W \max$, and walking distance), and changes in mean values after 3 and 6 months from baseline, are presented in table 2 . No statistically significant differences were found in baseline assessment parameters of exercise tolerance between group $\mathrm{RC}$ and group $\mathrm{CR}$ (table 3).

No significant group effects were found. Significant time effects and interaction of time with group were found in endurance time during cycling at $75 \% \mathrm{~W} \max$ (cycling endurance time), $f \mathrm{C}$ during cycling at $60 \% \mathrm{Wmax}$ ( $f \mathrm{C}$ during cycling) and walking distance. Post hoc analysis revealed a significantly increased cycling endurance time and walking distance, and a significantly decrea- sed $f \mathrm{C}$ during cycling in group $\mathrm{RC}$ compared to group $\mathrm{CR}$; significant interactions of time with groups were found (table 3). Analysis of covariance (ANCOVA) revealed a significant effect of diagnosis for $f \mathrm{C}$ during cycling and walking distance (test statistic $(F)=17.59$; degrees of freedom $(\mathrm{df})=1,60 ; \mathrm{p}=0.0001$; and $\mathrm{F}=15,5$; $\mathrm{df}=1.51 ; \mathrm{p}=0.0003$; respectively). Table 4 indicates that patients with asthma and patients with COPD showed comparable responses in heart rate during measurements at 3 and 6 months. However, such a trend was not seen for walking distance, suggesting that patients with asthma and patients with COPD responded differently during the 6 min walking test as a result of rehabilitation. ANCOVA revealed no significant effect of diagnosis for cycling endurance time $(\mathrm{F}=0.82 ; \mathrm{df}=1,57$; $\mathrm{p}=0.37$ ).

Within-group analysis for the patients first receiving

Table 3. - Results of statistical analysis for all patients (asthma and COPD) between groups RC and CR with respect to the variables endurance time during cycling, cardiac frequency during cycling, and walking distance measured at baseline, over 6 months (to-t6), and over the first 3 months (to-t3)

\begin{tabular}{|c|c|c|c|c|c|c|}
\hline \multirow[t]{2}{*}{ Variable } & \multirow[t]{2}{*}{$\begin{array}{l}\text { Baseline } \\
\text { measurements }\end{array}$} & \multicolumn{3}{|c|}{$\begin{array}{c}\text { ANOVA }^{\dagger} \\
(t 0-t 6)\end{array}$} & \multicolumn{2}{|c|}{$\begin{array}{l}\text { Post hoc analysis } \ddagger \\
\qquad(t 0-t 3)\end{array}$} \\
\hline & & $\mathrm{G}$ & $\mathrm{T}$ & $\mathrm{T} \times \mathrm{G}$ & $\mathrm{T}$ & $\mathrm{T} \times \mathrm{G}$ \\
\hline \multicolumn{7}{|l|}{ Exercise tolerance } \\
\hline \multirow{3}{*}{$\begin{array}{l}\text { Endurance time during cycling at } 75 \% \\
W \max \mathrm{s}\end{array}$} & (NS; 0.70) & $\mathrm{df}=1,58$ & $\mathrm{df}=2,116$ & $\mathrm{df}=2,116$ & $\mathrm{df}=1,58$ & $\mathrm{df}=1,58$ \\
\hline & & $\mathrm{F}=1.39$ & $\mathrm{~F}=49.55$ & $\mathrm{~F}=48.52$ & $\mathrm{~F}=54.73$ & $\mathrm{~F}=56.74$ \\
\hline & & (NS; 0.24) & $(<0.0001)$ & $(<0.0001)$ & $(<0.0001)$ & $(<0.0001)$ \\
\hline \multirow{3}{*}{$\begin{array}{l}f \mathrm{C} \text { during cycling at } 60 \% \\
W \text { max beats } \cdot \mathrm{min}^{-1}\end{array}$} & (NS; 0.98) & $\mathrm{df}=1,61$ & $\mathrm{df}=2,122$ & $\mathrm{df}=2,122$ & $\mathrm{df}=1,61$ & $\mathrm{df}=1,61$ \\
\hline & & $\mathrm{F}=0.05$ & $\mathrm{~F}=18.13$ & $\mathrm{~F}=10.74$ & $\mathrm{~F}=9.04$ & $\mathrm{~F}=6.74$ \\
\hline & (Nc. 028 ) & (NS;0.83) & $(<0.0001)$ & $(0.0001)$ & $\begin{array}{l}(0.004) \\
d f-152\end{array}$ & $\begin{array}{c}(0.01) \\
d f-152\end{array}$ \\
\hline \multirow{2}{*}{ Walking distance $\mathrm{m}$} & & $\mathrm{F}=0.93$ & $\mathrm{~F}=22.43$ & $\begin{array}{c}\mathrm{F}=3.66 \\
\mathrm{f}=2,104\end{array}$ & $\mathrm{~F}=16.38$ & $\mathrm{~F}=4.24$ \\
\hline & & (NS; 0.34) & $(<0.0001)$ & $(0.03)$ & $(0.002)$ & $(0.04)$ \\
\hline
\end{tabular}

The data presented are degrees of freedom $(\mathrm{df})$, test statistic $(\mathrm{F})$, and p-values in parentheses. ${ }^{+}:$Wilcoxon rank-sum test; ${ }^{\dagger}$ : analysis of variance (ANOVA) with repeated measurements; $\star$ : contrast analysis; G: group effects; $\mathrm{T}$ : time effects; $\mathrm{T} \times \mathrm{G}$ : time-group interaction; Ns: not significant (i.e. $\mathrm{p}>0.05$ ). For definitions see legends to tables 1 and 2. 
Table 4. - Baseline values and changes from baseline for patients with asthma and patients with COPD in the rehabilitation-control group $(\mathrm{RC})$ and in the control-rehabilitation group $(\mathrm{CR})$ with respect to exercise tolerance and quality of life

\begin{tabular}{|c|c|c|c|c|}
\hline \multirow[t]{2}{*}{ Variable } & \multirow[t]{2}{*}{ Group } & \multicolumn{3}{|c|}{ Measurements } \\
\hline & & Baseline & After 3 months & After 6 months \\
\hline \multicolumn{5}{|l|}{ Asthma } \\
\hline \multicolumn{5}{|l|}{ Exercise tolerance } \\
\hline \multirow{2}{*}{ Endurance time during cycling at $75 \% W \max \mathrm{s}$} & $\mathrm{RC}(\mathrm{n}=22)$ & $389 \pm 178$ & $427 \pm 240$ & $241 \pm 315$ \\
\hline & $\mathrm{CR}(\mathrm{n}=17)$ & $379 \pm 226$ & $-8 \pm 193$ & $463 \pm 214$ \\
\hline \multirow{2}{*}{$f \mathrm{C}$ during cycling at $60 \% \mathrm{~W} \max$ beats $\cdot \mathrm{min}^{-1}$} & $\mathrm{RC}(\mathrm{n}=22)$ & $144 \pm 22$ & $-8 \pm 14$ & $-6 \pm 13$ \\
\hline & CR $(n=18)$ & $139 \pm 21$ & $-1 \pm 7$ & $-11 \pm 9$ \\
\hline \multirow[t]{2}{*}{ Walking distance $\mathrm{m}$} & $\mathrm{RC}(\mathrm{n}=18)$ & $598 \pm 126$ & $63 \pm 89$ & $82 \pm 103$ \\
\hline & CR (n=17) & $639 \pm 132$ & $8 \pm 63$ & $68 \pm 64$ \\
\hline \multicolumn{5}{|l|}{ Quality of life } \\
\hline \multirow{2}{*}{ Dyspnoea score (range 5-35) } & $\mathrm{RC}(\mathrm{n}=22)$ & $18 \pm 7$ & $6 \pm 5$ & $8 \pm 5$ \\
\hline & $\mathrm{CR}(\mathrm{n}=20)$ & $18 \pm 5$ & $1 \pm 3$ & $7 \pm 5$ \\
\hline \multirow[t]{2}{*}{ Fatigue score (range 4-28) } & $\mathrm{RC}(\mathrm{n}=22)$ & $15 \pm 5$ & $4 \pm 5$ & $5 \pm 6$ \\
\hline & CR $(n=21)$ & $17 \pm 5$ & $0 \pm 3$ & $4 \pm 6$ \\
\hline \multirow[t]{2}{*}{ Emotion score (range 7-49) } & $\mathrm{RC}(\mathrm{n}=22)$ & $28 \pm 8$ & $6 \pm 7$ & $8 \pm 9$ \\
\hline & $\mathrm{CR}(\mathrm{n}=21)$ & $32 \pm 7$ & $0 \pm 5$ & $4 \pm 8$ \\
\hline \multirow[t]{2}{*}{ Mastery score (range 4-28) } & $\mathrm{RC}(\mathrm{n}=22)$ & $19 \pm 6$ & $3 \pm 4$ & $4 \pm 5$ \\
\hline & $\mathrm{CR}(\mathrm{n}=21)$ & $23 \pm 5$ & $0 \pm 3$ & $1 \pm 3$ \\
\hline \multicolumn{5}{|l|}{$\begin{array}{l}\text { COPD } \\
\text { Exercise tolerance }\end{array}$} \\
\hline Exercise tolerance & & & & \\
\hline \multirow[t]{2}{*}{ Endurance time during cycling at $75 \% W \max s$} & $\mathrm{RC}(\mathrm{n}=13)$ & $356 \pm 191$ & $399 \pm 221$ & $170 \pm 344$ \\
\hline & $\mathrm{CR}(\mathrm{n}=8)$ & $349 \pm 142$ & $6 \pm 182$ & $418 \pm 241$ \\
\hline \multirow[t]{2}{*}{$f_{\mathrm{C}}$ during cycling at $60 \% \mathrm{~W} \max$ beats $\cdot \mathrm{min}^{-1}$} & $\mathrm{RC}(\mathrm{n}=15)$ & $120 \pm 19$ & $-7 \pm 10$ & $-4 \pm 11$ \\
\hline & $\mathrm{CR}(\mathrm{n}=8)$ & $125 \pm 9$ & $0 \pm 55$ & $-8 \pm 5$ \\
\hline \multirow[t]{2}{*}{ Walking distance $\mathrm{m}$} & $\mathrm{RC}(\mathrm{n}=12)$ & $480 \pm 99$ & $51 \pm 57$ & $25 \pm 61$ \\
\hline & $\mathrm{CR}(\mathrm{n}=7)$ & $494 \pm 78$ & $46 \pm 43$ & $72 \pm 76$ \\
\hline \multicolumn{5}{|l|}{ Quality of life } \\
\hline \multirow[t]{2}{*}{ Dyspnoea score (range 5-35) } & $\mathrm{RC}(\mathrm{n}=14)$ & $19 \pm 4$ & $6 \pm 5$ & $5 \pm 8$ \\
\hline & $\mathrm{CR}(\mathrm{n}=8)$ & $19 \pm 4$ & $0 \pm 2$ & $5 \pm 4$ \\
\hline \multirow[t]{2}{*}{ Fatigue score (range 4-28) } & $\mathrm{RC}(\mathrm{n}=15)$ & $17 \pm 5$ & $5 \pm 5$ & $4 \pm 6$ \\
\hline & $\mathrm{CR}(\mathrm{n}=8)$ & $18 \pm 4$ & $0 \pm 2$ & $3 \pm 4$ \\
\hline \multirow[t]{2}{*}{ Emotion score (range 7-49) } & $\mathrm{RC}(\mathrm{n}=15)$ & $31 \pm 8$ & $5 \pm 8$ & $5 \pm 9$ \\
\hline & CR (n=8) & $33 \pm 6$ & $2 \pm 4$ & $3 \pm 4$ \\
\hline \multirow[t]{2}{*}{ Mastery score (range 4-28) } & $\mathrm{RC}(\mathrm{n}=15)$ & $18 \pm 6$ & $4 \pm 4$ & $4 \pm 5$ \\
\hline & CR (n=8) & $20 \pm 4$ & $-1 \pm 2$ & $2 \pm 2$ \\
\hline
\end{tabular}

Values are expressed as the mean \pm SD. For definitions see legends to tables 1 and 2.

the rehabilitation programme and then the control condition (group RC) showed that the cycling endurance time, $f \mathrm{C}$ during cycling, and the walking distance improved significantly during the rehabilitation period compared to the control period $(\mathrm{p}<0.004)$. Furthermore, patients receiving first the control condition and then the rehabilitation programme (group CR) improved significantly during the rehabilitation period in terms of cycling endurance time and $f \mathrm{C}$ during cycling compared to the control period $(\mathrm{p}<0.0008)$. No significant improvements were found in walking distance (group CR; $\mathrm{p}=0.09$ ).

The within-group comparison for $\mathrm{RC}$ revealed significant follow-up effects in terms of cycling endurance time, $f \mathrm{C}$ during cycling, and walking distance $(\mathrm{p}<0.009)$. With the exception of a significant decline in cycling endurance time $(p=0.0001)$ between measurements at the third and sixth month, no such differences were found for $f \mathrm{C}$ during cycling and walking distance $(\mathrm{p}>0.11)$.

\section{Quality of life}

Mean values of baseline QOL of the CRDQ (i.e. dyspnoea, fatigue, emotion and mastery), and changes in mean values after 3 and 6 months from baseline, are shown in table 2 . With the exception of the mastery dimension, no significant differences were found in baseline QOL between group RC and group CR (table 5).

No significant group effects were found. Significant time effects and interaction of time with group were found in the dimensions dyspnoea, fatigue, emotion and mastery. Post hoc analysis revealed significant improvements in the above-mentioned dimensions in group RC compared to group CR (table 5). ANCOVA revealed no significant effect of diagnosis for these dimensions (dyspnoea: $\mathrm{F}=0.12 ; \mathrm{df}=1,61 ; \mathrm{p}=0.73$; fatigue: $\mathrm{F}=2.65$; $\mathrm{df}=1,63 ; \mathrm{p}=0.11$; emotion: $\mathrm{F}=1.17 ; \mathrm{df}=1,63 ; \mathrm{p}=0.28$; and mastery: $\mathrm{F}=2.21 ; \mathrm{df}=1,63 ; \mathrm{p}=0.14)$, indicating that patients with asthma and COPD showed similar responses in QOL as a result of rehabilitation.

Within-group analysis for RC showed that all dimensions of the CRDQ improved significantly during the rehabilitation period compared to the control period $(\mathrm{p}<0.0006)$. In addition, within-group analysis for CR revealed significant improvements during the rehabilitation period compared to the control period in terms of dyspnoea, fatigue and mastery $(\mathrm{p}<0.005)$. 
Table 5. - Results of statistical analysis for all patients (asthma and COPD) between groups RC and CR with respect to the variables dyspnoea, fatigue, emotion, and mastery of the CRDQ measured at baseline, over 6 months $(t 0-t 6)$, and over the first 3 months (to-t3)

\begin{tabular}{|c|c|c|c|c|c|c|}
\hline \multirow[t]{2}{*}{ Variable } & \multirow[t]{2}{*}{$\begin{array}{c}\text { Baseline } \\
\text { measurements* }\end{array}$} & \multicolumn{3}{|c|}{$\begin{array}{l}\mathrm{ANOVA} * * \\
(t 0-t 6)\end{array}$} & \multicolumn{2}{|c|}{$\begin{array}{l}\text { Post-hoc analysis } * * * \\
\qquad(t 0-t 3)\end{array}$} \\
\hline & & G & $\mathrm{T}$ & $\mathrm{T} \times \mathrm{G}$ & $\mathrm{T}$ & $\mathrm{T} \times \mathrm{G}$ \\
\hline \multicolumn{7}{|l|}{ Quality of life } \\
\hline \multirow{3}{*}{ Dyspnoea score (range 5-35) } & (NS; 0.94) & $\mathrm{df}=1,62$ & $\mathrm{df}=2,124$ & $\mathrm{df}=2,124$ & $\mathrm{df}=1,62$ & $\mathrm{df}=1,62$ \\
\hline & & $\mathrm{F}=2.90$ & $\mathrm{~F}=58.53$ & $\mathrm{~F}=12.75$ & $\mathrm{~F}=47.83$ & $\mathrm{~F}=25.30$ \\
\hline & & (Ns; 0.09) & $(<0.0001)$ & $(<0.0001)$ & $(<0.0001)$ & $(<0.0001)$ \\
\hline \multirow[t]{3}{*}{ Fatigue score (range 4-28) } & (NS;0.23) & $\mathrm{df}=1,64$ & $\mathrm{df}=2,128$ & $\mathrm{df}=2,128$ & $\mathrm{df}=1,64$ & $\mathrm{df}=1,64$ \\
\hline & & $\mathrm{F}=0.05$ & $\mathrm{~F}=25.77$ & $\mathrm{~F}=6.85$ & $\mathrm{~F}=23.58$ & $\mathrm{~F}=15.79$ \\
\hline & & (NS; 0.82) & $(<0.0001)$ & $(0.002)$ & $(<0.0001)$ & $(0.0002)$ \\
\hline \multirow[t]{3}{*}{ Emotion score (range 7-49) } & (NS; 0.11) & $\mathrm{df}=1,64$ & $\mathrm{df}=2,128$ & $\mathrm{df}=2,128$ & $\mathrm{df}=1,64$ & $\mathrm{df}=1,64$ \\
\hline & & $\mathrm{F}=0.02$ & $\mathrm{~F}=20.27$ & $\mathrm{~F}=4.38$ & $\mathrm{~F}=15.92$ & F9.50 \\
\hline & & (NS; 0.94) & $(<0.0001)$ & $(0.03)$ & $(0.002)$ & $(0.002)$ \\
\hline \multirow[t]{3}{*}{ Mastery score (range 4-28) } & $(0.03)$ & $\mathrm{df}=1,64$ & $\mathrm{df}=2,128$ & $\mathrm{df}=2,128$ & $\mathrm{df}=1,64$ & $\mathrm{df}=1,64$ \\
\hline & & $\mathrm{F}=0.43$ & $\mathrm{~F}=21.82$ & $\mathrm{~F}=11.89$ & $\mathrm{~F}=14.48$ & $\mathrm{~F}=23.25$ \\
\hline & & (NS; 0.52) & $(<0.0001)$ & $(<0.0001)$ & $(0.0003)$ & $(<0.0001)$ \\
\hline
\end{tabular}

The data presented are degrees of freedom (df), test statistic $(\mathrm{F})$, and p-values in parenthesis. *: Wilcoxon rank-sum test; **: analysis of variance (ANOVA) with repeated measurements; ***: contrast analysis; G: group effects; T: time effects; T $\times \mathrm{G}$ : timegroup interaction; ns: not significant (i.e. $\mathrm{p}>0.05$ ). CRDQ: Chronic Respiratory Disease Questionnaire. For further definitions see legend to table 1.

The within-group comparison for $\mathrm{RC}$ revealed significant follow-up effects for the dimensions dyspnoea, fatigue, emotion and mastery $(\mathrm{p}<0.0002)$. Measurements of QOL showed no significant differences between the third and the sixth month ( $\mathrm{p}>0.08)$.

\section{Relationship between exercise tolerance and quality of life}

No significant Spearman's rank correlation coefficients between baseline exercise tolerance (i.e. cycling endurance time, $f \mathrm{C}$ during cycling, and walking distance) and baseline scores of QOL (i.e. dyspnoea, fatigue, emotion and mastery) were found for the 66 patients (range -0.21 to $0.21 ; \mathrm{p}>0.1$ ). In addition, no significant Spearman's rank correlation coefficients were found between changes in exercise tolerance and changes in QOL as measured over the first 3 months for group RC (range -0.39 to $0.33 ; \mathrm{p}>0.02$ ).

\section{Discussion}

One important feature of the present study is that this multifaceted rehabilitation programme was run by skilled, local physiotherapists. In the Netherlands, treatment of patients with (severe) asthma or COPD is generally available in a limited number of multidisciplinary rehabilitation centres. The results of this study demonstrate statistically significant improvements in exercise tolerance and QOL following a community based rehabilitation programme including drug treatment, compared to drug treatment alone.

A major limitation of the present study concerns the high number of patients dropping out after randomization. However, additional statistical analysis, including the 23 patients who dropped out after randomization, revealed similar differences in efficacy in terms of exercise tolerance and QOL. This analysis was based on the assumption that for the above-mentioned patients measurements at the third and sixth month showed no changes compared to baseline measurements.

\section{Exercise tolerance}

This study revealed substantial improvements in cycling endurance time (by $421 \mathrm{~s}$ ) in favour of the patients receiving the rehabilitation programme. Similar improvements in cycling endurance time were found both in asthmatics (by 435 s) and patients with COPD (by 393 s). These findings supported previous studies in a mixed group of patients after a 3 month out-patient rehabilitation programme [12], and in patients with COPD after an 8 week in-patient rehabilitation programme followed by a 16 week out-patient programme [1].

In addition, the present rehabilitation programme led to substantial improvements in walking distance (by 39 $\mathrm{m})$ in favour of the patients receiving the rehabilitation programme (the minimum clinically important difference for the 6 min walking test has been estimated to be $30 \mathrm{~m} \mathrm{[20]).} \mathrm{This} \mathrm{is} \mathrm{in} \mathrm{accordance} \mathrm{with} \mathrm{the} \mathrm{findings}$ of Goldstein et al. [1], who showed that the patients receiving rehabilitation walked $38 \mathrm{~m}$ more during a 6 min walking test than the patients receiving conventional treatment. In addition, Gosselink et al. [12] showed that patients receiving rehabilitation walked $58 \mathrm{~m}$ more during a 6 min walking test than the patients receiving drug treatment. By means of ANCOVA, the present study demonstrated a significant difference in walking distance between patients with asthma and COPD over 6 months. On the basis of the data presented in table 4 , it can be seen that the patients with asthma who received the rehabilitation programme in the first 3 months improved their walking distance by $55 \mathrm{~m}$ in comparison with the asthmatic patients who received the control condition during the first 3 months. In contrast, the COPD patients in the RC group improved by only $5 \mathrm{~m}$ compared to the $\mathrm{CR}$ group at 3 months. This difference 
in response to rehabilitation might be explained by differences in severity of disease between the patients with asthma and COPD or by the imbalance in the number of patients in the groups (patients with asthma: 18 in group RC and 17 in group CR; patients with COPD: 12 in group $\mathrm{RC}$ and 7 in group $\mathrm{CR}$ ).

This study demonstrated a significantly lower $f \mathrm{C}$ on the cycle ergometer in favour of the patients receiving the rehabilitation programme. CASABURI et al. [13] showed that patients with COPD who trained at a high intensity on a cycle ergometer had a significantly lower $f \mathrm{C}$ after a 2 month exercise training programme than those who trained at a low intensity. In other studies, however, no significant changes in $f \mathrm{C}$ as evaluated by means of a submaximal cycle ergometer test were found [12, 21]. This might be related either to the severity of the disease or to the intensity of the training programme applied. The heterogeneous group of patients in the current study had relatively mild disease and less ventilatory limitation in comparison with patients in other studies, in which no decreases in $f \mathrm{C}$ were found [12, 21]. This should have allowed for true aerobic conditioning in the patients in the present study. With respect to training intensity, it was found that, on the basis of a continuous $f \mathrm{C}$ registration of each patient during one training session, the patients, on average, met the training regimen proposed by the American College of Sports Medicine Position Stand [22], i.e. at least $30 \mathrm{~min}$ with a $f \mathrm{C}$ above approximately $60 \%$ of maximal $f \mathrm{C}$ (i.e. 56 min above $60 \%$ of maximal $f \mathrm{C}$; range $21-82 \mathrm{~min}$ ).

The present study demonstrated significant improvements in cycling endurance time, $f \mathrm{C}$ during cycling, and walking distance at follow-up assessments compared to baseline assessments. However, the cycling endurance time dropped off significantly between the third and the sixth month. In a mixed group of patients, Gosselink et al. [12] showed that the 6 min walking distance and the cycling endurance time continued to improve after rehabilitation. In a mixed group of patients, Cox et al. [23] demonstrated significant improvements after a 3 month rehabilitation programme in maximal load during cycling and 12 min walking distance in comparison with a control group. The maximal workload and walking distance decreased gradually during subsequent assessments at 3,9 and 21 months after rehabilitation, but remained significantly higher in the patients receiving the rehabilitation programme. STRIJBOS et al. [7] demonstrated, up to 3 months after a 3 month hospital-based out-patient rehabilitation programme in a group of COPD patients, significant improvements in maximal workload during cycling and 4 min walking distance compared to baseline assessments. A similar tendency was observed for patients who received a 3 month home-based rehabilitation programme in combination with 24 sessions in a local physiotherapy practice. However, the latter patients continued to improve their maximal workload and walking distance up to 15 months after finishing the rehabilitation programme.

In other studies, the rehabilitation programme was followed by a structured exercise maintenance programme [2, 24]. VALE et al. [24] observed that although the 12 min walking distance decreased significantly after finishing a 6 week rehabilitation programme, the walking distance measured $11 \pm 6$ months (range 3-21 months) after rehabilitation remained significantly greater than at baseline. They did not find significant additional differences in walking distance between patients who received a structured exercise maintenance programme after rehabilitation compared to patients who did not. RIES et al. [2] demonstrated that benefits in treadmill walking endurance, though decreasing progressively after a 2 month rehabilitation programme, persisted up to 16 months after rehabilitation. In the latter study, monthly reinforcement sessions were held for 1 year. Future studies should determine whether or not structured exercise maintenance programmes are necessary in order to sustain gains in exercise tolerance after rehabilitation.

\section{Quality of life}

A number of studies have reported significant differences between groups in QOL in a mixed group of patients [12] and in patients with COPD [1, 3], in favour of the groups receiving the rehabilitation programme. These differences were found for the dimensions dyspnoea, emotion and mastery [12], and dyspnoea, fatigue, emotion and mastery of the CRDQ $[1,3]$, respectively. A change in score in dyspnoea of 2.5 points, in fatigue and mastery of 2.0 points, and in emotion of 3.5 points, has been associated with a minimally important change in health-related quality of life [25]. The improvements in the present study in total CRDQ score between group $\mathrm{RC}$ and group CR of the mixed group (17 points), asthma patients (17 points), and patients with COPD (18 points), in favour of the patients receiving the rehabilitation programme, are substantial. The between-group improvement in total CRDQ score in the studies by GolDSTEIN et al. [1] and WIJKSTRA and co-workers [3] amounted to 14 points.

Only a few investigators have examined the long-term benefits of pulmonary rehabilitation programmes in terms of QOL. In agreement with the findings of GossELINK and co-workers [12], this study showed significant follow-up effects in the dyspnoea dimension. In addition, the study revealed significant effects at follow-up in the dimensions fatigue, emotion and mastery. VALE et al. [24] noticed, in a group of COPD patients, that the overall CRDQ score, measured $11 \pm 6$ months (range $3 \pm$ 21 months) after finishing the rehabilitation programme, remained significantly greater than baseline scores. WIJKSTRA et al. [26] demonstrated that 9 months after finishing a 3 month home-based rehabilitation programme, including 2 weekly sessions in a local physiotherapy practice, patients receiving once monthly physiotherapy maintenance sessions showed significantly better CRDQ scores (i.e. fatigue, emotion and mastery) than a group receiving no physiotherapy maintenance sessions. Moreover, since the latter study showed no reduction in CRDQ scores at follow-up assessments in combination with small decreases in walking distance in the group receiving once monthly maintenance sessions, it appears that gains in QOL are retained more than gains in exercise tolerance. The results of the present study also suggest that benefits in the CRDQ dimensions measured after 6 months are retained more than benefits in exercise tolerance. 


\section{Relationship between exercise tolerance and quality of life}

There is some evidence that improvements in exercise tolerance may transfer to performance of activities of daily living and QOL [1, 3, 14, 27, 28]. However, RIES et al. [29] failed to find an improvement in activities of daily living involving hand and arm movements, despite improvements in endurance tolerance on an arm cycle ergometer, after a programme of supported and unsupported upper extremity training. The results of the study by WIJKSTRA and co-workers [3] and the results of the present study did not reveal significant correlation coefficients between baseline exercise tolerance and baseline QOL, or between improvements in exercise tolerance and improvements in QOL.

The findings of the present study cannot be attributed to single therapeutic components. Further research is required to determine the relative efficacy of each of the programmes' components [30]. Finally, the further development of valid, reliable and sensitive health-related QOL instruments (cf. JonEs et al. [31]), and the application of these instruments in future studies, may provide insight into whether or not an improvement in exercise tolerance carries over to performance of activities of daily living. If such a relationship cannot be confirmed, patients should be rehabilitated in the performance of those specific tasks which most handicap them in their daily life $[32,33]$.

\section{Summary}

A multifaceted rehabilitation programme run in local physiotherapy practices improved the exercise tolerance and quality of life of a heterogeneous group of asthmatic patients and patients with chronic obstructive pulmonary disease. Additional analysis indicated that asthmatic patients and patients with chronic obstructive pulmonary disease show similar responses to rehabilitation, with the exception of walking distance. These findings may have important consequences for the quality of basic care for patients with asthma or chronic obstructive pulmonary disease. Treatment in pulmonary rehabilitation centres should be confined to patients needing more specialized help. Community-based rehabilitation programmes can be offered to patients with mild to moderately severe obstruction of the airways.

Acknowledgements: The authors would like to express their gratitude to the participating physiotherapists, general practitioners, pulmonary physicians, and district nurses in Amsterdam and surroundings for their contribution in directing the rehabilitation programme, to H.A.A.M. Gosselink for his preparatory work and advice, to the National Health Insurance Council for subsidizing and supporting this study, and to Glaxo bv. for the supply of mini-Wright peak flow meters.

\section{References}

1. Goldstein RS, Gort EH, Stubbing D, Avendano MA, Guyatt GH. Randomised controlled trial of respiratory rehabilitation. Lancet 1994; 19: 1394-1397.
2. Ries AL, Kaplan RM, Limberg TM, Prewitt LM. Effects of pulmonary rehabilitation on physiologic and psychosocial outcomes in patients with chronic obstructive pulmonary disease. Ann Intern Med 1995; 122: 823-832.

3. Wijkstra, PJ, van Altena R, Kraan J, Otten V, Postma DS, Koëter GH. Quality of life in patients with chronic obstructive pulmonary disease improves after rehabilitation at home. Eur Respir J 1994; 7: 269-273.

4. Ries AL. Position paper of the American Association of Cardiovascular and Pulmonary Rehabilitation. Scientific basis of pulmonary rehabilitation. J Cardiopulm Rehabil 1990; 10: 418-441.

5. Belman MJ. Pulmonary rehabilitation in chronic respiratory insufficiency. 2. Exercise in patients with chronic obstructive pulmonary disease. Thorax 1993; 48: 936-946.

6. Cambach W, Chadwick-Straver RVM, Wagenaar RC, van Keimpema ARJ, Kemper HCG, Rijswijk H. Feasibility of a pulmonary rehabilitation programme in community-based physiotherapy practices. J Rehabil Sci 1994; 7: 104-112.

7. Strijbos JH, Postma DS, Altena van R, Gimeno F, Koëter GH. A comparison between an out-patient hospital-based pulmonary rehabilitation program and a homecare pulmonary rehabilitation program in patients with COPD: a follow-up of 18 months. Chest 1996; 109: 366-372.

8. Guyatt GH, Belman LB, Townsend M, Plugsley SO, Chambers LW. A measure of quality of life for clinical trials in chronic lung disease. Thorax 1987; 42: 773-778.

9. Quanjer PH. Standardized lung function testing. Report of working party for "Standardization of Lung Function Tests". European community Coal and Steel, Luxembourg. Bull Eur Physiopathol Respir 1983; 19 (Suppl. 5): $1-95$.

10. Jones NL, Summers E, Killian KJ. Influence of age and stature on exercise capacity during incremental cycle ergometry in men and women. Am Rev Respir Dis 1989; 140: 1373-1380.

11. Borg GAV. Psychophysical basis of perceived exertion. Med Sci Sports Exerc 1982; 14: 377-811.

12. Gosselink HAAM, Wagenaar RC, Keimpema van ARJ, Chadwick-Straver RVM. The effect of a rehabilitation programme on patients with obstructive lung disease (Het effect van een revalidatieprogramma bij patiënten met CARA). Ned Tijdschr Fysiother 1990; 100: 193199.

13. Casaburi R, Patessio A, Ioli F, Zanaboni S, Donner CF, Wasserman K. Reductions in exercise lactic acidosis and ventilation as a result of exercise training in patients with obstructive lung disease. Am Rev Respir Dis 1991; 143: 9-18.

14. Simpson K, Killian K, McCartney N, Stubbing DG, Jones NL. Randomised controlled trial of weightlifting exercise in patients with chronic airflow limitation. Thorax 1992; 47: 70-75.

15. Åstrand PO, Rodahl K. In: Textbook of Work Physiology. New York, McGraw-Hill, 1986.

16. McGavin CR, Gupta SP, McHardy GJR. Twelve minute walking tests for assessing disability in chronic bronchitis. Br Med J 1976; 1: 822-823.

17. Guyatt GH, Pugsley SO, Sullivan MJ, et al. Effect of encouragement on walking test performance. Thorax 1984; 39: 818-822.

18. Mungall IPF, Hainsworth R. Assessment of respiratory function in patients with chronic obstructive airways disease. Thorax 1979; 34: 254-258. 
19. Alison JA, Samios R, Anderson SD. Evaluation of exercise training in patients with chronic airway obstruction. Phys Ther 1981; 61: 1273-1277.

20. Guyatt GH, Townsend M, Pugsley SO, et al. Bronchodilators in chronic airflow limitation. Am Rev Respir Dis 1987; 135: 1069-1074.

21. Vyas MN, Banister EW, Morton JW, Grzybowski S. Response to exercise in patients with chronic airway obstruction. 1. Effects of exercise training. Am Rev Respir Dis 1971; 103: 390-399.

22. American College of Sports Medicine Position Stand. The recommended quantity and quality of exercise for developing and maintaining cardiorespiratory and muscular fitness in healthy adults. Med Sci Sports Exerc 1990; 22: 265-274.

23. Cox NJ, Hendricks JC, Binkhorst RA, van Herwaarden CLA. A pulmonary rehabilitation program for patients with asthma and mild chronic obstructive pulmonary disease (COPD). Lung 1993; 171: 235-244.

24. Vale F, Reardon JZ, ZuWallack RL. The long-term benefits of out-patient pulmonary rehabilitation on exercise endurance and quality of life. Chest 1993; 103: 42-45.

25. Jaeschke R, Singer J, Guyatt GH. Measurement of health status: ascertaining the minimum clinically important difference. Controlled Clin Trials 1989; 10: 407415.

26. Wijkstra PJ, TenVergert EM, van Altena R, et al. Long- term benefits of rehabilitation at home on quality of life and exercise tolerance in patients with chronic obstructive pulmonary disease. Thorax 1995; 50: 824-828.

27. Busch AJ, McClements JD. Effects of a supervised home exercise program on patients with severe chronic obstructive pulmonary disease. Phys Ther 1988; 68: 469-474.

28. Niederman MS, Clemente PH, Fein AM, et al. Benefits of a multidisciplinary pulmonary rehabilitation program. Chest 1991; 99: 798-804.

29. Ries AL, Ellis B, Hawkins RWH. Upper extremity exercise training in chronic obstructive pulmonary disease. Chest 1988; 93: 688-692.

30. Gosselink HAAM, Wagenaar RC, Rijswijk H, Sargeant AJ, Decramer MLA. Diaphragmatic breathing reduces efficiency of breathing in patients with chronic obstructive pulmonary disease. Am J Respir Crit Care Med 1995; 151: 1136-1142.

31. Jones PW, Quirk FH, Baveystock CM. The St. George's Respiratory Questionnaire. Resp Med 1991; 85 (Suppl. B): $25-31$.

32. Wagenaar RC, Meijer OG. Effects of stroke rehabilitation. J Rehabil Sci 1991; 4: 61-73.

33. Gosselink HAAM, Wagenaar RC. Efficacy of breathing exercises in chronic obstructive pulmonary disease and asthma; a meta-analysis of literature. J Rehabil Sci 1993; 6: 66-79. 